\title{
Pregnancy outcomes in women with a systemic right ventricle and transposition of the great arteries results from the ESC-EORP Registry of Pregnancy and Cardiac disease (ROPAC)
}

\author{
Oktay Tutarel (1) , ${ }^{1}$ Lucia Baris, ${ }^{2}$ Werner Budts, ${ }^{3}$ Mohamad Gamal Abd-El Aziz, ${ }^{4}$ \\ Csilla Liptai, ${ }^{5}$ David Majdalany, ${ }^{6}$ Silvana Jovanova, ${ }^{7}$ Alexandra Frogoudaki, ${ }^{8}$ \\ Heidi M Connolly, ${ }^{9}$ Mark R Johnson, ${ }^{10}$ Aldo P Maggioni (1) , ${ }^{11}$ Roger Hall, ${ }^{12}$ \\ Jolien W Roos-Hesselink (1) , ${ }^{2}$ on behalf of the ROPAC Investigators Group
}

- Additional supplemental material is published online only. To view, please visit the journal online (http://dx.doi. org/10.1136/heartjnl-2020318685).

For numbered affiliations see end of article.

Correspondence to Prof Jolien W Roos-Hesselink, Cardiology, ErasmusMC, 3000 CA Rotterdam, Netherlands; j.roos@erasmusmc.nl

OT and LB are joint first authors.

Received 18 November 2020 Revised 25 February 2021 Accepted 8 March 2021

Published Online First 28 April 2021

\section{ABSTRACT}

Objective Cardiac disease is a major cause of maternal mortality. Data regarding pregnancy outcomes in women with a systemic right ventricle (sRV) are scarce. We studied pregnancy outcomes in women with an SRV after the atrial switch procedure for transposition of the great arteries (TGA) or congenitally corrected TGA (CCTGA). Methods The ESC EORP Registry of Pregnancy and Cardiac Disease is an international prospective registry of pregnant women with cardiac disease. Pregnancy outcomes (maternal/fetal) in all women with an sRV are described. The primary end point was a major adverse cardiac event (MACE) defined as maternal death, supraventricular or ventricular arrhythmias requiring treatment, heart failure, aortic dissection, endocarditis, ischaemic coronary event and other thromboembolic events.

Results Altogether, 162 women with an sRV (TGA $n=121$, CCTGA $n=41$, mean age $28.8 \pm 4.6$ years) were included. No maternal mortality occurred. In 26 women, at least one MACE occurred, heart failure in $16(9.8 \%)$, arrhythmias (atrial 5, ventricular 6) in 11 $(6.7 \%)$ and others in 4 (2.5\%). Prepregnancy signs of heart failure as well as an sRV ejection fraction $<40 \%$ were predictors of MACE. One woman experienced fetal loss, while no neonatal mortality was observed. No significant differences were found between women with CCTGA and TGA. In the subset of women who had an echocardiogram before and after pregnancy, no clear deterioration in sRV was observed.

Conclusion The majority of women with an sRV tolerated pregnancy well with a favourable maternal and fetal outcome. Heart failure and arrhythmias were the most common MACE.

\section{INTRODUCTION}

In patients with transposition of the great arteries after the atrial switch procedure (TGA), the morphological right ventricle (RV) acts as the systemic ventricle. The same holds true for patients with congenitally corrected transposition of the great arteries (CCTGA). Ongoing concerns have been expressed about the long-term ability of the systemic RV (sRV) to support systemic pressure and its capacity to handle the volume load of pregnancy. ${ }^{12}$ However, there is a paucity of information about pregnancy outcomes in women with an sRV. ${ }^{13}$ Retrospective studies, in the majority from single centres, provided conflicting information. ${ }^{45}$ Large prospective studies are lacking. Yet, these studies are needed to provide evidence for guidelines on the management of pregnancy in women with an sRV and to counsel women who are contemplating pregnancy. The aim of this study is to assess in a prospective worldwide study, maternal and fetal outcomes of pregnancy in women with an sRV.

\section{METHODS}

\section{Study design}

The European Society of Cardiology (ESC) EURObservational Research Programme (EORP) Registry on Pregnancy and Cardiac disease (ROPAC) is an international, prospective, observational registry of pregnant patients with structural or ischaemic heart disease, aortic pathology and pulmonary arterial hypertension. Study design and methods have been described in detail previously. ${ }^{6}$

ROPAC was initiated by the ESC working groups on congenital heart disease and valvular heart disease in 2007 and embedded in the EORP of the ESC. Pregnant patients were included prospectively from 2007 and for this analysis we included all pregnancies in patients with an sRV enrolled between January 2007 and January 2018. Women with a univentricular circulation were excluded.

\section{Data}

The ROPAC study protocol and the first results of this registry were published in $2013 .^{6}$ Patients with a diagnosis of TGA or CCTGA were identified from the registry. Baseline characteristics collected before pregnancy included age, New York Heart Association (NYHA) functional classification, ECG rhythm, diagnosis, risk factors (smoking habits, hypertension, diabetes), medication, previous interventions, parity and obstetric history and echocardiographic measurements. Information regarding the ejection fraction ( $>$ or $<40 \%$ ) of the sRVwhich was assessed by echocardiography-was 
mandatory, while additional information, for example, tricuspid regurgitation, was collected, but was not mandatory. Countries were divided into high-income or emerging countries according to the International Monetary Fund Classification. ${ }^{7}$

\section{Definitions and end points}

The primary combined end point was the occurrence of a major adverse cardiac event (MACE), defined as combined end point of maternal death, supraventricular or ventricular arrhythmias requiring treatment, heart failure, aortic dissection, endocarditis, ischaemic coronary event and other thromboembolic events. The secondary end points were adverse obstetric outcomes and adverse fetal/neonatal outcomes. Heart failure was defined according to the American College of Cardiology/American Heart Association guidelines, ${ }^{8}$ and heart failure episodes were only included when they required hospital admission, new treatment or change in the existing treatment regimen. Impaired systemic ventricular function was defined as an sRV ejection fraction $<40 \%$. Postpartum haemorrhage was defined as increased blood loss during delivery up to 24 hours post partum requiring specific interventions. Haemolysis, elevated liver enzymes, low platelets (HELLP) syndrome, pre-eclampsia and eclampsia and pregnancy-induced hypertension were defined according to the International Society for the Study of Hypertension in Pregnancy 2012 statement. ${ }^{9}$ Fetal mortality was defined as the death of a fetus after 20 weeks of gestation until birth. Neonatal mortality was defined as the death of a live-born baby in the first 6 months of life. Premature birth was defined as birth before 37 weeks of gestation. Low birth weight was defined as a birth weight of $<2500$ g. Low Apgar score was defined as an Apgar score at 5 min of $<7$. All outcomes were examined for the duration of the pregnancy and up to 6 months post partum.

\section{Patient and public involvement}

This research was done without patient involvement.

\section{Statistical analysis}

Data are presented as mean values and SD if normally distributed and median with IQR if skewed. Categorical data are presented as frequencies and percentages. Baseline characteristics and outcomes were compared between women with TGA and CCTGA with $\chi^{2}$ tests, Fisher's exact tests, Student's t-tests and Mann-Whitney $U$ tests where appropriate. Comparisons between prepregnancy and postpartum echocardiograms were performed with the McNemar's test. Univariable analyses to identify baseline characteristics associated with outcomes were performed. Predictors used were the prepregnancy variables: age, parity, diagnosis, CCTGA, country, signs of heart failure, NYHA class $>1$, sRV end-diastolic diameter $>42 \mathrm{~mm}$, sRV ejection fraction $<40 \%$ and pulmonary hypertension. Missing values were handled with multiple imputation. A $p$ value of $<0.05$ (two-sided test) was considered significant. All statistical tests and analyses were performed with SPSS V.21.0 (SPSS, Chicago, Illinois, USA).

\section{RESULTS}

Of the 5739 patients included in the ROPAC registry from January 2007 to January 2018, ${ }^{10} 162$ women had an sRV (TGA after atrial switch $n=121$ and CCTGA $n=41$ ). None of the CCTGA patients had a history of tricuspid valve surgery. Mean age was $28.8 \pm 4.6$ years, and 86 women $(52.8 \%)$ were primigravida. Baseline characteristics are presented in table 1 for the whole cohort and for TGA and CCTGA patients, respectively. Most of the women were asymptomatic or had only mild symptoms (NYHA class I/II) before pregnancy. Only one woman in the TGA group was in NYHA class III. Women with TGA received cardiac medication before pregnancy in $30.6 \%$ and those with CCTGA in 39\%. Outcomes of pregnancy are presented in tables 2 and 3. Maternal mortality did not occur during pregnancy or up until 6 months postdelivery. Of all patients with an sRV, hospital admission for a cardiac reason was required in 9.8\% during pregnancy. This occurred more often in women with CCTGA than TGA $(19.5 \%$ vs $6.6 \%, p=0.03)$. The main reason for hospital admissions was heart failure for both groups. The majority of heart failure episodes occurred in the second and third trimester (9/16 events), while one took place in the first trimester. Post partum, six women had heart failure episodes (three in the first week post partum, two within 1 month and one within 6 months). Out of these, three already had heart failure episodes during pregnancy. At baseline, sinus rhythm was present in 123 patients (76\%), while a pacemaker rhythm was reported in 14 (8.6\%). Out of these 14,7 had a CCTGA. Of the 14 women with pacemaker rhythm, 3 hospital admissions for cardiac reasons occurred (1 for heart failure during pregnancy and 2 for arrhythmias). There was no fetal death in this subgroup, however, six preterm deliveries occurred, of which two had a low Apgar score. Supraventricular tachycardia occurred in five $(3.1 \%)$ patients, and ventricular tachycardia in six $(3.7 \%)$ patients.

Both, a prepregnancy and postpartum echocardiogram with information of RV dimensions was present in 40 women. At prepregnancy, 27 out of 40 women had a dilated RV (end-diastolic

Table 1 Baseline characteristics

\begin{tabular}{|c|c|c|c|c|}
\hline & $\begin{array}{l}\text { Systemic RV } \\
\text { All }(n=162)\end{array}$ & $\begin{array}{l}\text { CCTGA } \\
(n=41)\end{array}$ & TGA after atrial switch $(n=121)$ & $P$ value \\
\hline Age in years (mean, SD) & $28.8(4.6)$ & $28.0(5.9)$ & $29.1(4.0)$ & 0.22 \\
\hline Living in an emerging country & $15(9.2)$ & $8(19.5)$ & $7(5.8)$ & 0.02 \\
\hline Primigravida & $86(52.8)$ & $22(53.7)$ & $64(52.9)$ & 1.00 \\
\hline Current smoking & $7(5.0)$ & $2(5.4)$ & $5(5.0)$ & 1.00 \\
\hline Prior diabetes mellitus & $2(1.2)$ & $0(0)$ & $2(1.7)$ & 1.00 \\
\hline Prior hypertension & $2(1.2)$ & $1(2.4)$ & $1(0.8)$ & 0.43 \\
\hline Signs of heart failure before pregnancy & $8(4.9)$ & $3(7.3)$ & $5(4.1)$ & 0.42 \\
\hline Cardiac medication before pregnancy & $53(32.5)$ & $16(39.0)$ & $37(30.6)$ & 0.34 \\
\hline Systemic RV dilatation & $41(25.3)$ & $13(31.7)$ & $28(23.1)$ & 0.30 \\
\hline Systemic RV ejection fraction $<40 \%$ & $44(27.0)$ & $9(22.0)$ & $35(28.9)$ & 0.42 \\
\hline Pulmonary hypertension & $4(2.5)$ & $1(2.4)$ & $3(25)$ & 0.99 \\
\hline
\end{tabular}

Values are $\mathrm{n}(\%)$ if not otherwise stated. $\mathrm{P}$ value for comparison between CCTGA and TGA

CCTGA, congenitally corrected transposition of the great arteries; RV, right ventricle 
Table 2 Maternal outcomes of pregnancy

\begin{tabular}{|c|c|c|c|c|}
\hline & $\begin{array}{l}\text { Systemic RV } \\
\text { All }(n=162)\end{array}$ & $\begin{array}{l}\text { CCTGA } \\
(n=41)\end{array}$ & $\begin{array}{l}\text { TGA after atrial } \\
\text { switch }(n=121)\end{array}$ & $P$ value \\
\hline $\begin{array}{l}\text { Maternal mortality } \leq 6 \text { months post } \\
\text { partum }\end{array}$ & $0(0)$ & $0(0)$ & $0(0)$ & n.a. \\
\hline $\begin{array}{l}\text { Hospital admission for a cardiac } \\
\text { reason }\end{array}$ & $16(9.8)$ & $8(19.5)$ & $8(6.6)$ & 0.03 \\
\hline Heart failure & $16(9.8)$ & $5(12.2)$ & $11(9.1)$ & 0.56 \\
\hline Supraventricular tachycardia & $5(3.1)$ & $0(0)$ & $5(4.1)$ & 0.33 \\
\hline Ventricular tachycardia & $6(3.7)$ & $2(4.9)$ & $4(3.3)$ & 0.64 \\
\hline Thromboembolic events & $3(1.8)$ & $2(4.9)$ & $1(0.8)$ & 0.16 \\
\hline Endocarditis & $1(0.6)$ & $1(2.4)$ & $0(0)$ & 0.25 \\
\hline Pregnancy-induced hypertension & $7(4.3)$ & $2(4.9)$ & $5(4.1)$ & 1.00 \\
\hline (Pre-)eclampsia or HELLP & $3(1.8)$ & $0(0)$ & $3(2.5)$ & 0.57 \\
\hline Postpartum haemorrhage & $11(6.7)$ & $3(7.3)$ & $8(6.6)$ & 1.00 \\
\hline
\end{tabular}

CCTGA, congenitally corrected transposition of the great arteries; HELLP, haemolysis elevated liver enzymes low CCTGA, congenitally corrected transposition of the gre
platelet count; n.a., not available; RV, right ventricle.

diameter $>40 \mathrm{~mm})$. At the postpartum echocardiogram, 31 women had a dilated RV $(\mathrm{p}=0.34)$. Out of the group with a dilated RV, three improved, while seven with a normal diameter prepregnancy deteriorated to the dilated group. Information regarding tricuspid regurgitation (TR) at prepregnancy was available in 64 women (CCTGA $n=17$, TGA 47). Out of the CCTGA group, 3 women (17.6\%) had no or mild TR, while $14(82.4 \%)$ had moderate-to-severe TR. These numbers were $33(70.2 \%)$ and $14(29.8 \%)$ for the TGA group, respectively $(p=0.01$ for CCTGA vs TGA). Prepregnancy and postpartum information regarding TR were available in 46 women. Out of these at prepregnancy no or mild TR was present in 28 , and moderate-to-severe TR in 18. Post partum these numbers were 29 and 17, respectively. Two women out of the no or mild TR group deteriorated to moderate TR, while in three women with moderate TR at prepregnancy no or mild TR was present post partum.

A caesarean section was performed in $46.7 \%$ of the whole ROPAC cohort compared with $48.5 \%$ of women with an sRV. ${ }^{10}$ It was more common with $61 \%$ in women with CCTGA compared with $44.6 \%$ of women with TGA, although not statistically significant $(p=0.19)$. Of the 79 women who underwent caesarean section, 26 did so because of cardiac reasons. Most common reasons were heart failure $(n=6,23 \%)$, severity of cardiac disease $(n=9,34 \%)$, dysrhythmias $(n=4,15 \%)$ and anticoagulation use $(n=2,8 \%)$. Fetal death was not reported in women with CCTGA, and occurred in one woman with TGA, while it occurred in $1.3 \%$ of all women included in ROPAC. ${ }^{10}$ There were 34 premature births, out of these 15 were induced labours and 12 spontaneous (7 unknown). Preterm birth was not

Table 3 Obstetric and fetal outcomes of pregnancy

\begin{tabular}{lllll}
\hline & $\begin{array}{l}\text { Systemic RV } \\
\text { All }(\mathbf{n = 1 6 2})\end{array}$ & $\begin{array}{l}\text { CCTGA } \\
(\mathbf{n}=41)\end{array}$ & $\begin{array}{l}\text { TGA after atrial } \\
\text { switch }(\mathbf{n}=121)\end{array}$ & P value \\
\hline Caesarean section & $79(48.5)$ & $25(61.0)$ & $54(44.6)$ & 0.07 \\
\hline $\begin{array}{l}\text { Of which for cardiac reasons } \\
\text { Emergency caesarean section }\end{array}$ & $26(32.9)$ & $14(56.0)$ & $12(22.2)$ & 0.01 \\
for cardiac reasons & $6(3.7)$ & $3(7.3)$ & $3(2.5)$ & 0.17 \\
\hline Fetal death & $1(0.6)$ & $0(0)$ & $1(0.8)$ & 1.00 \\
Neonatal death & $0(0)$ & $0(0)$ & $0(0)$ & n.a. \\
\hline Premature birth & $34(21.0)$ & $8(20.0)$ & $26(21.5)$ & 1.00 \\
\hline IUGR & $7(4.3)$ & $1(2.4)$ & $6(5.0)$ & 0.68 \\
\hline Low Apgar scores & $12(7.4)$ & $3(7.3)$ & $9(7.4)$ & 1.00 \\
\hline Small for gestational age & $29(17.8)$ & $7(17.1)$ & $22(18.2)$ & 1.00 \\
\hline
\end{tabular}

Values are $\mathrm{n}(\%)$.

CCTGA, congenitally corrected transposition of the great arteries; IUGR, intrauterine growth retardation; n.a., not available; $\mathrm{RV}$, right ventricle. significantly associated with maternal heart failure $(p=0.15)$ or higher NYHA class $(p=0.16)$, but was significantly associated with maternal (cardiac) medication use $(p=0.01)$. Of the 34 women who delivered preterm, 10 were using cardiac medication during pregnancy compared with 10 of the 116 who did not deliver preterm (online supplemental table 1). In 12 women data on prematurity was missing. Women with an sRV gave birth to babies with low birth weight in $17.8 \%$ vs $11.7 \%$ for the whole ROPAC cohort. ${ }^{10}$ Low birthweight infants were born to women with CCTGA in $17.1 \%$ vs $18.2 \%$ in women with TGA $(p=0.87)$.

\section{Predictors of adverse outcomes}

Results of univariable logistic regression analyses are presented in figure 1. Prepregnancy signs of heart failure as well as a RV ejection fraction $<40 \%$ were predictors of MACE, while being primigravida reduced the risk.

\section{DISCUSSION}

This international prospective registry studies the outcomes of pregnancy in women with an sRV. Our contemporary data show that a majority of women with an sRV tolerate pregnancy well with relatively low rates of MACE and without maternal or neonatal mortality (figure 2). Fetal mortality occurred in only one $(0.6 \%)$ patient. Still, heart failure occurred in approximately $10 \%$ of women during pregnancy, while arrhythmias were observed in $6.7 \%$. With the exception of hospital admissions for cardiac reasons, which were more common in women with CCTGA, there was no significant difference regarding maternal or fetal outcome between women with CCTGA and TGA.

\section{Maternal outcome}

The results of this first large prospective study support the data from the few retrospective studies that reported no maternal mortality related to pregnancy in women with an sRV. ${ }^{4} 511$ Only one study of 70 pregnancies in 40 women reported severe sRV failure leading to cardiac transplantation after delivery in one woman, and another case in which the woman developed heart failure and then died suddenly 1 month after delivery. ${ }^{12}$ In this later study, there was a higher number of patients with a decreased RV function prior to pregnancy compared with our cohort. ${ }^{12}$ A number of complications such as arrhythmias, heart failure and symptomatic baffle obstructions have been described in women with an sRV during pregnancy. ${ }^{5}{ }^{13}$ Most frequently, arrhythmias and heart failure are encountered with a rate between $7 \%-22 \%$ and $7 \%-21 \%$, respectively, depending on the study design and patient population. ${ }^{512-14}$ In our contemporary registry, these numbers were lower with arrhythmias occurring in around $7 \%$ of women and heart failure in $10 \%$. When comparing the cohorts from previously published reports with our cohort, striking differences are not present. On univariate analysis, predictors of MACE were signs of heart failure before pregnancy as well as an sRV ejection fraction $<40 \%$. In most of the previous studies due to the small number of women included or the retrospective design, predictors of adverse maternal outcome were not reported. However, the numbers in our study are too small to perform multivariate analysis.

\section{Obstetric and fetal outcome}

In our contemporary cohort, both obstetric and fetal complications were less frequent than reported by previous studies. 512

The most frequent observed fetal morbidity was premature birth (20.9\%), followed by low birth weight (17.8\%). While one fetal loss was observed, there was no neonatal mortality. These 


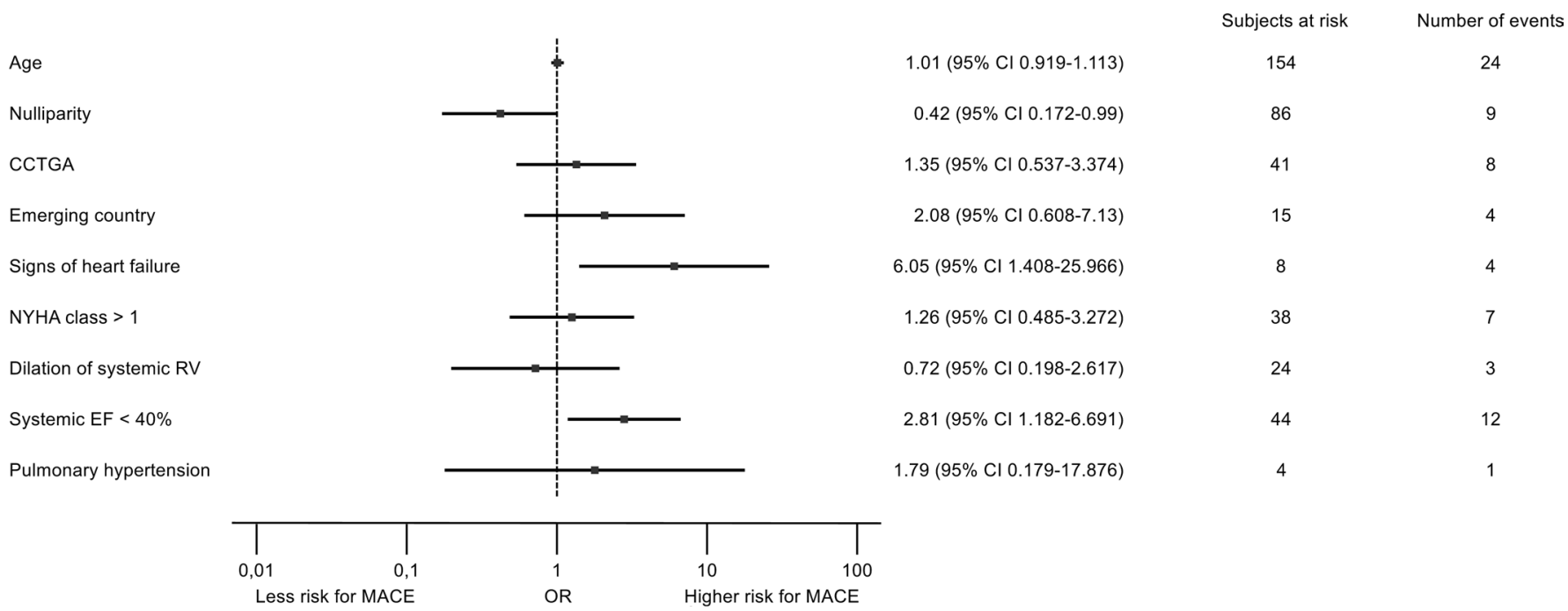

Figure 1 Predictors of adverse maternal outcome. Forest plot illustrating the results of the univariate logistic regression analysis for adverse maternal outcome, defined as MACE. CCTGA, congenitally corrected transposition of the great arteries; EF, ejection fraction; MACE, major adverse cardiac events; NYHA, New York Heart Association; RV, right ventricle.

numbers compare favourably with pregnancy outcomes of other cardiac disease like hypertrophic cardiomyopathy or aortic stenosis. ${ }^{15} 16$ Likewise, they are lower than those reported by a study from the Dutch ZAHARA registry, where premature birth was observed in $31.4 \%$, and being small for gestational age in $21.6 \% .^{5}$ Likewise, a multicentre, retrospective study from the USA reported rates of 31\% for low birth weight, and 39\% for premature birth. ${ }^{12}$ Fetal and neonatal mortality was also higher in the Dutch registry (combined 11.8\%)..$^{5}$

Pregnancy-induced hypertensive disorder occurred in seven women (4.3\%), while HELLP or (pre-)eclampsia was observed in three $(1.8 \%)$. In the study by Drenthen et al, ${ }^{5}$ hypertensive disorders were more common (18.4\%), including cases of pre-eclampsia and HELLP (10.2\%). Similarly, Canobbio et al observed hypertensive disorders in $17 \%$ of women. ${ }^{12}$

A caesarean section was performed in $48.5 \%$ of women with an sRV in our study. Whether the (high) rates in our study are attributable to women having an sRV is not certain, but it is probable that women with heart disease in general are handled with more care and apprehension by treating physicians and are thus given a caesarean section (as many physicians prefer this apparently more controlled environment). Furthermore, the use of caesarean section as primary mode of delivery is very country and centre dependent.

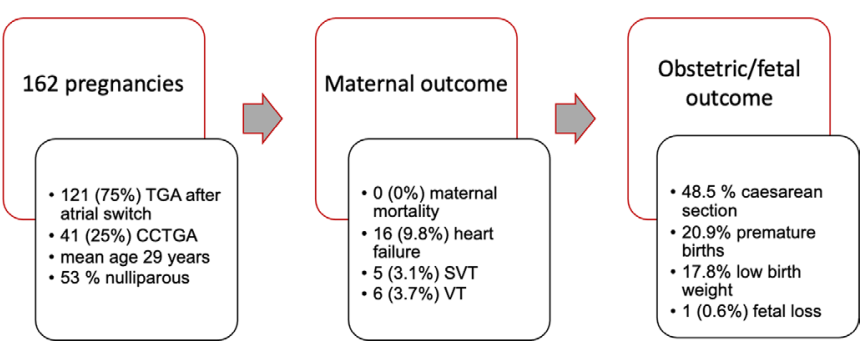

Figure 2 Maternal and fetal outcome. CCTGA, congenitally corrected transposition of the great arteries; SVT, supraventricular tachycardia; VT, ventricular tachycardia.

\section{CCTGA versus TGA after atrial switch}

No significant differences in pregnancy outcome were found between women with CCTGA and TGA in the current study. Only hospital admission for a cardiac reason occurred more often in women with CCTGA than TGA $(19.5 \%$ vs $6.6 \%, \mathrm{p}=0.03)$. Published data comparing pregnancy outcomes between women with CCTGA and TGA are scarce. A retrospective study from London/UK reported the results of 14 women with an sRV, of which 11 had TGA and 3 had CCTGA. Cardiac complications occurred only in women with TGA. ${ }^{14}$ Connolly et al reported the Mayo Clinic experience with pregnancy among women with CCTGA. ${ }^{3}$ Additionally, a more contemporary cohort from Poland was studied by Kowalik et al. ${ }^{17}$ Both reported a similar or more favourable outcome for women with CCTGA during pregnancy compared with reports of women with TGA.

Serial echocardiographic data were only available in a limited number of women. Therefore, analysis regarding the course and outcome of sRV ejection fraction was not possible. However, in 40 women with prepregnancy and postpartum sRV dimensions, $54 \%$ of those with a normal measurement at prepregnancy, dilated post partum. In a study by Cataldo et al, worsening of ventricular function was encountered in $29 \%$ of pregnant women with an sRV, of which $50 \%$ recovered during follow-up. ${ }^{18}$ An earlier study reported the echocardiographic data on the sRV dimensions in 18 pregnancies, ${ }^{2} 5$ women (31\%) experienced worsening of their RV dimensions during 7 pregnancies. While this progression in RV size was noted during or after a first pregnancy in four cases, it occurred after a second pregnancy in one, and a third pregnancy in two. ${ }^{2}$ Our results indicate that being primigravida reduced the risk of MACE. Maybe the sRV is able to tolerate the haemodynamic strain of one pregnancy but is less capable to tolerate the repeated strains posed by a second or third pregnancy. In addition, the sRV is known to deteriorate with age, and some of the observed deterioration with repeated pregnancy may be related simply to the passage of time. ${ }^{19}$ In one smaller study, the rate of deterioration was similar between women who became pregnant and those who did not after 8 years of follow-up. ${ }^{18}$ A larger comparative study of matched cohorts of women who have and have not undergone pregnancy over the same period would clarify whether pregnancy accelerates the 
rate of deterioration or not. Such a study would be particularly interesting with a long-term follow-up. An additional explanation besides the challenges of an sRV could be that peripartum cardiomyopathy also may play a role in some women.

The majority of the women with an sRV in our study had TGA. This is likely to change in the future, because the introduction of the arterial switch operation was a game changer for this population, which leads to a circulation, where the left ventricle is supporting the systemic circulation. Therefore, in the future most women with an sRV and a biventricular circulation will have CCTGA.

A limitation of our study is that serial echocardiographic data were only available in a limited number of women, and even in those was not complete. Therefore, analysis regarding the course and outcome of sRV ejection fraction as well as systemic atrioventricular valve regurgitation was not possible. But information regarding sRV dimensions was available. Additionally, all echocardiography parameters were obtained and assessed by the investigators from the including centre, inducing a possible interobserver variability for which we could not correct. Despite these limitations, this prospective registry included the largest number of women with sRV reported so far, providing important information related to the maternal and fetal outcome in women with an sRV.

\section{CONCLUSIONS}

In conclusion, women with an sRV tolerate pregnancy surprisingly well with a favourable maternal and fetal outcome. Risk factors were prepregnancy signs of heart failure as well as an sRV ejection fraction $<40 \%$. Dedicated studies focusing on RV function and tricuspid valve regurgitation are warranted.

\section{Key messages}

\section{What is already known on this subject?}

- In patients with transposition of the great arteries after the atrial switch procedure as well as patients with congenitally corrected transposition of the great arteries, the morphological right ventricle acts as the systemic ventricle.

- Ongoing concerns have been expressed about the long-term ability of the systemic right ventricle to handle the volume load of pregnancy.

- There is a paucity of information about pregnancy outcomes in these women.

\section{What might this study add?}

- In this prospective, multicentre study on pregnancy outcomes in women with a systemic right ventricle, it was found that pregnancy is surprisingly well tolerated but that a systemic ejection fraction $<40 \%$ and clinical signs of heart failure prior to pregnancy were risk factors of maternal complications during pregnancy.

\section{How might this impact on clinical practice?}

- Our results can reassure providers and patients with a systemic right ventricle that pregnancy is well tolerated if reduced ventricular function and clinical signs of heart failure are absent.

\section{Author affiliations}

'Department of Congenital Heart Disease and Paediatric Cardiology, German Heart Centre Munich, TUM School of Medicine, Technical University of Munich; DZHK (German Centre for Cardiovascular Research), partner site Munich Heart Alliance, Munich, Germany
${ }^{2}$ Department of Cardiology, Erasmus Medical Center Rotterdam, Rotterdam, The Netherlands

${ }^{3}$ Department of Cardiology, University Hospital Leuven, Leuven, Belgium

${ }^{4}$ Cardiology, CCU, Assiut General Hospital, Assiut, Egypt

${ }^{5}$ Department of Cardiology, Semmelweis University Medical Center, Budapest,

Hungary

${ }^{6}$ Department of Cardiology, Cleveland Clinic, Cleveland, Ohio, USA

${ }^{7}$ Department of Cardiology, University Clinic of Cardiology, University t Cyril and Methodius, Skopje, North Macedonia

${ }^{8}$ Department of Cardiology, Adult Congenital Heart Clinic, Attikon University Hospital, Athens, Greece

${ }^{9}$ Department of Cardiology, University of Rochester Medical Center, New York, New York, USA

${ }^{10}$ Department of Obstetric Medicine and Gynaecology, Imperial College London, Chelsea and Westminster Hospital, London, UK

${ }^{11}$ EURObservational Research Programme, European Society of Cardiology, France and Maria Cecilia Hospital, GVM Care \& Research, Cotignola, Italy

${ }^{12}$ Department of Cardiology, University of East Anglia Norwich Medical School, Norwich, UK

Acknowledgements The authors would like to thank all ROPAC investigators and the EORP team. EORP oversight Committee, ROPAC Executive Committee, Data collection was conducted by the EORP department from the ESC by Elin Folkesson Lefrancq as Project Officer; Viviane Missiamenou, Gérard Gracia and Sebastien Authier as Data Managers. Results of this study have been presented at the ESC Congress 2020 of the European Society of Cardiology (European Heart Journal, Volume 41, Issue Supplement_2:2218).

Collaborators The ROPAC Investigators Group: EORP Oversight Committee: Christopher Peter Gale, Chair, GB, Branko Beleslin, RS, Andrzej Budaj, PL, Ovidiu Chioncel, RO, Nikolaos Dagres, DE, Nicolas Danchin, FR, David Erlinge, SE, Jonathan Emberson, GB, Michael Glikson, IL, Alastair Gray, GB, Meral Kayikcioglu, TR, Aldo Maggioni, IT, Klaudia Vivien Nagy, HU, Aleksandr Nedoshivin, RU, Anna-Sonia Petronio, IT, Jolien Roos-Hesselink, NL, Lars Wallentin, SE, Uwe Zeymer, DE. Executive Committee. Roger Hall GB (Co-Chair), Jolien Roos-Hesselink NL (Co-Chair), Joerg Stein, AT, William Anthony Parsonage, AU, Werner Budts, BE, Julie De Backer, BE, Jasmin Grewal, CA, Ariane Marelli, CA, Harald Kaemmerer, DE, Guillaume Jondeau, FR, Mark Johnson, GB, Aldo P. Maggioni, IT, Luigi Tavazzi, IT, Ulf Thilen, SE, Uri Elkayam, US, Catherine Otto, US, Karen Sliwa, ZA. ROPAC Investigators: ARGENTINA—Buenos Aires: A. Aquieri, A. Saad, H. Ruda Vega, J. Hojman, J.M. Caparros, M. Vazquez Blanco. AUSTRALIA—Elizabeth Vale: M. Arstall, C.M. Chung, G. Mahadavan, E. Aldridge, M. Wittwer, Y.Y. Chow, Herston: W.A. Parsonage, K. Lust, New Lambton Heights: N. Collins, G. Warner, R. Hatton, A. Gordon, E. Nyman. AUSTRIA—Innsbruck: J. Stein, E. Donhauser, Vienna: H. Gabriel. AZERBAIJAN—Baku: A. Bahshaliyev, F. Guliyev, I. Hasanova, T. Jahangirov, Z. Gasimov. BANGLADESHDhaka: A. Salim, C.M. Ahmed, F. Begum, M.H. Hoque, M. Mahmood, M.N. Islam, P.P. Haque, S.K. Banerjee, T. Parveen. BELGIUM—Brussels: M. Morissens, Gent: J. De Backer, L. Demulier, M. de Hosson, Leuven:W. Budts, M. Beckx. BOSNIA AND HERZEGOVINA—Banja Luka: M. Kozic, M. Lovric, T. Kovacevic-Preradovic. BULGARIA—Sofia: N. Chilingirova, P. Kratunkov. CANADA—Edmonton: N. Wahab, S. McLean, Hamilton, Ontario: E. Gordon, L. Walter, Montreal: A. Marelli, A. R. Montesclaros COLOMBIA—Medellin: G. Monsalve, C. Rodriguez, F. Balthazar, V. Quintero, W. Palacio, L.A. Mejía Cadavid, E. Munoz Ortiz, F. Fortich Hoyos, E. Arevalo Guerrero, J. Gandara Ricardo, J. Velasquez Penagos. CZECH REPUBLIC—Hradec Kralove: Z. Vavera, Prague: J. Popelova. DENMARK —Copenhagen: N. Vejlstrup, L. Grønbeck, M. Johansen, A. Ersboll. EGYPT—Alexandria: Y. Elrakshy, Assiut: K. Eltamawy, M. Gamal Abd-El Aziz, Benha: A. El Nagar, H. Ebaid, H. Abo Elenin, M. Saed, S. Farag, W. Makled, Cairo: K. Sorour, Z. Ashour, G. El-Sayed, M. Abdel Meguid Mahdy, Minia: N. Taha, A. Dardeer, M. Shabaan, Zagazig: A. Saad, M. Ali. FRANCENice: P. Moceri, Paris: G. Duthoit, M. Gouton, J. Nizard, L. Baris, S. Cohen, M. Ladouceur, D. Khimoud, B. lung. GERMANY —Berlin: F. Berger, A. Olsson, Bonn: U. Gembruch, W.M. Merz, E. Reinert, S. Clade, Y. Kliesch, Essen: C. Wald, Hamburg: C. Sinning, R. Kozlik-Feldmann, S. Blankenberg, E. Zengin-Sahm, G. Mueller, M. Hillebrand, P. Hauck, Y. von Kodolitsch, N. Zarniko, Muenster: H. Baumgartner, R. Schmidt, A. Hellige, Munich: O. Tutarel, H. Kaemmerer, B. Kuschel, N. Nagdyman, Oldenburg: R. Motz. GEORGIA—Tbilisi: D. Maisuradze. GREECE—Athens: A. Frogoudaki, E. lliodromitis, M. Anastasiou-Nana, Marousi, D. Triantafyllis, G. Bekiaris, Thessaloniki: H. Karvounis, G. Giannakoulas, D. Ntiloudi, S.A. Mouratoglou. HUNGARY—Budapest: A. Temesvari, H. Balint, D. Kohalmi, B. Merkely, C. Liptai, Szeged: A. Nemes, T. Forster, A. Kalapos, K. Berek, K. Havasi, N. Ambrus. INDIAKarad: A. Shelke, R. Kawade, S. Patil. INDONESIA—Bandung: E. Martanto, T.M. Aprami, A. Purnomowati, C.J. Cool, M. Hasan, R. Akbar, S. Hidayat, T.I. Dewi, W. 
Permadi, D.A. Soedarsono. IRAN—Tehran: M.M. Ansari-Ramandi, N. Samiei, A. Tabib, F. Kashfi, S. Ansari-Ramandi, S. Rezaei. IRAQ—Baghdad: H. Ali Farhan, A. Al-Hussein, G. Al-Saedi, G. Mahmood, I.F. Yaseen, L. Al-Yousuf, M. AlBayati, S. Mahmood, S. Raheem, T. AlHaidari, Z. Dakhil. IRELAND—Dublin: P. Thornton, J. Donnelly, M. Bowen. ISRAEL—Beer Yakov: A. Blatt, G. Elbaz-Greener, Hadera: A. Shotan, Haifa: S. Yalonetsky, Rehovot: S. Goland, M. Biener. ITALY—Bologna: G. Egidy Assenza, M. Bonvicini, A. Donti, A. Bulgarelli, D. Prandstraller, Bolzano: C. Romeo, R. Crepaz, Brescia: E. Sciatti, M. Metra, R. Orabona, Massa: L. Ait Ali, P. Festa, Milan: V. Fesslova, C. Bonanomi, M. Calcagnino, F. Lombardi, A.M. Colli, M.W. Ossola, C. Gobbi, E. Gherbesi, L. Tondi, M. Schiavone, M. Squillace, Palermo: M.G. Carmina, Torino: A. Maina, C. Macchi, E. Gollo, F.M. Comoglio, N. Montali, P. Re, R. Bordese, T. Todros, V. Donvito, W. Grosso Marra, Trieste: G. Sinagra, B. D'Agata Mottolese, M. Bobbo, V. Gesuete, S. Rakar, F. Ramani. JAPAN—Chiba: K. Niwa. KAZAKHSTAN—Almaty: D. Mekebekova, A. Mussagaliyeva, T. Lee. KYRGYZSTAN—Bishkek: E. Mirrakhimov, S. Abilova, E. Bektasheva, K. Neronova, O. Lunegova. LITHUANIA—Kaunas: R. Žaliūnas, R. Jonkaitienè, J. Petrauskaitè, Vilnius: A. Laucevicius, D. Jancauskaite, L. Lauciuviene, L. Gumbiene, L. Lankutiene, S. Glaveckaite, M. Laukyte, S. Solovjova, V. Rudiene. MALAYSIA—Kuala Lumpur: K.H. Chee, C.C-W. Yim, H.L. Ang, R. Kuppusamy, T. Watson. MALTA—Birkirkara: M. Caruana. NORWAY—Oslo: M-E. Estensen. PAKISTAN—Rawalpindi: M.G.A. Mahmood Kayani, R. Munir. POLAND—Bialystok: A. Tomaszuk-Kazberuk, B. Sobkowicz, J. Przepiesc, Krakow: A. Lesniak-Sobelga, L. Tomkiewicz-Pajak, M. Komar, M. Olszowska, P. Podolec, S. Wisniowska-Smialek, Lodz: M. Lelonek, U. Faflik, A. CichockaRadwan, Poznan: K. Plaskota, O. Trojnarska. PORTUGAL—Coimbra: N. Guerra, Lisboa: L. de Sousa, Porto: C. Cruz, V. Ribeiro. REPUBLIC OF MACEDONIA—Skopje: S. Jovanova. ROMANIA—Bucharest: V. Petrescu, R. Jurcut, C. Ginghina, I. Mircea Coman, M. Musteata. RUSSIA—Belgorod: O. Osipova, T. Golivets, I. Khamnagadaev, O. Golovchenko, A. Nagibina, I. Ropatko, Izhevsk: I.R. Gaisin, L. Valeryevna Shilina, Moscow: N. Sharashkina, SaintPetersburg: E. Shlyakhto, O. Irtyuga, O. Moiseeva, E. Karelkina, I. Zazerskaya, A. Kozlenok, I. Sukhova. SERBIA—Belgrade: L. Jovovic. SLOVENIA—Ljubljana: K. Prokšelj, M. Koželj. SOMALILAND—Hargeisa: A.O. Askar, A.A. Abdilaahi, M.H. Mohamed, A.M. Dirir. SOUTH AFRICA —Cape Town: K. Sliwa, Houghton: P. Manga. SPAIN—Barcelona: A. Pijuan-Domenech, L. Galian-Gay, P. Tornos, M.T. Subirana, M. T. Subirana, Bilbao: N. Murga, Madrid: J. M. Oliver, B. Garcia-Aranda Dominguez, I. Hernandez Gonzalez, J.F. Delgado Jimenez, P. Escribano Subias. SUDAN—Khartoum: A. Elbushi, A. Suliman, K. Jazzar, M. Murtada, N. Ahamed. SWEDEN—Göteborg: M. Dellborg, E. Furenas, M. Jinesjo, K. Skoglund, P. Eriksson, T. Gilljam, Lund: U. Thilen. SWITZERLAND—Basel: D. Tobler, Bern: K. Wustmann, F. Schwitz, M. Schwerzmann, Lausanne: T. Rutz, J. Bouchardy, Zurich: M. Greutmann, B.M. Santos Lopes, L. Meier, M. Arrigo. THE NETHERLANDS—Amsterdam: K. de Boer, T. Konings, Enschede: E. Wajon, L.J. Wagenaar, Geldrop: P. Polak, Groningen: E.PG. Pieper, Rotterdam: J. RoosHesselink, L. Baris, I. van Hagen, H. Duvekot, J.M.J. Cornette, The Hague: C. De Groot, Utrecht: C. van Oppen. TURKEY — Istanbul: L. Sarac, O. Batukan Esen, S. Catirli Enar. UGANDAKampala: C. Mondo, P. Ingabire, B. Nalwanga, T. Semu. UNITED ARAB EMIRATESAbu Dhabi: B.T. Salih, W.A.R. Almahmeed, S. Wani, F.S. Mohamed Farook, Al Ain, F. Gerges, A.M. Komaranchath, F. Al bakshi, Dubai: A. Al Mulla, A.H. Yusufali, E.I. Al Hatou, N. Bazargani, F. Hussain. UNITED KINGDOM—Birmingham: L. Hudsmith, P. Thompson, S. Thorne, S. Bowater, Buckinghamshire: A. Money-Kyrle, P. Clifford, P. Ramrakha, S. Firoozan, J. Chaplin, N. Bowers, Coventry: D. Adamson, London: F. Schroeder, R. Wendler, S. Hammond, P. Nihoyannopoulos, Norwich Norfolk: R. Hall, L. Freeman, Southampton: G. Veldtman, J. Kerr, L. Tellett. UNITED STATES—Boston: N. Scott, A.B. Bhatt, D. DeFaria Yeh, M.A. Youniss, M. Wood, A.A. Sarma, S. Tsiaras, A. Stefanescu, J.M. Duran, L. Stone, Cleveland: D.S. Majdalany, J. Chapa, Detroit: K. Chintala, P. Gupta, Hershey, PA: J. Botti, J. Ting, W. R. Davidson, Lexington, Kentucky: G. Wells, D. Sparks, Mineola, NY: V. Paruchuri, K. Marzo, D. Patel, Minneapolis: W. Wagner, S.N. Ahanya, L. Colicchia, T. Jentink, K. Han, M. Loichinger, M. Parker, W. Wagner, C. Longtin, Omaha: A. Yetman, K. Erickson, J. Cramer, S. Tsai, B. Fletcher, S. Warta, Phoenix: C. Cohen, C. Lindblade, R. Puntel, K. Nagaran, N. Croft, Seattle: M. Gurvitz, C. Otto, Stanford, CA: C. Talluto, D. Murphy, M. G. Perlroth.

Contributors OT and LB contributed equally to this manuscript. Study design: JWR-H and RH. Data collection: all authors. Data analysis and statistical analysis: OT and LB. Manuscript draft: OT, LB and JWR-H. Critical revision, editing and approval of the final manuscript: all authors. OT, LB and JWR-H are responsible for the overall content as guarantors.

Funding Since the start of EORP, the following companies have supported the programme: Abbott Vascular Int. (2011-2021), Amgen Cardiovascular (20092018), AstraZeneca (2014-2021), Bayer AG (2009-2018), Boehringer Ingelheim (2009-2019), Boston Scientific (2009-2012), The Bristol Myers Squibb and Pfizer Alliance (2011-2019), Daiichi Sankyo Europe GmbH (2011-2020), The Alliance Daiichi Sankyo Europe GmbH and Eli Lilly and Company (2014-2017), Edwards
(2016-2019), Gedeon Richter Plc. (2014-2016), Menarini Int. Op. (2009-2012), MSD-Merck \& Co. (2011-2014), Novartis Pharma AG (2014-2020), ResMed (2014-2016), Sanofi (2009-2011), Servier (2009-2018), Vifor (2019-2022).

Competing interests WB reports a relationship with Proctor Abbott \& Occlutech. APM reports personal fees from Novartis, personal fees from Bayer, personal fees from Fresenius, outside the submitted work.

\section{Patient consent for publication Not required.}

Ethics approval When required, ethical approval or Institutional Review Board approval was obtained (eg, in Germany, the USA, Canada and Belgium). However, in some countries, the procedure to obtain ethical approval was waived because of the anonymised and untraceable nature of the data. Informed consent was obtained from patients if required by the local independent review board.

Provenance and peer review Not commissioned; externally peer reviewed.

Data availability statement All data relevant to the study are included in the article or uploaded as supplementary information. Data are owned by the ESC EURObservational Programme.

Supplemental material This content has been supplied by the author(s). It has not been vetted by BMJ Publishing Group Limited (BMJ) and may not have been peer-reviewed. Any opinions or recommendations discussed are solely those of the author(s) and are not endorsed by BMJ. BMJ disclaims all liability and responsibility arising from any reliance placed on the content. Where the content includes any translated material, BMJ does not warrant the accuracy and reliability of the translations (including but not limited to local regulations, clinical guidelines, terminology, drug names and drug dosages), and is not responsible for any error and/or omissions arising from translation and adaptation or otherwise.

Open access This is an open access article distributed in accordance with the Creative Commons Attribution 4.0 Unported (CC BY 4.0) license, which permits others to copy, redistribute, remix, transform and build upon this work for any purpose, provided the original work is properly cited, a link to the licence is given, and indication of whether changes were made. See: https://creativecommons.org/ licenses/by/4.0\%.

\section{ORCID iDs}

Oktay Tutarel http://orcid.org/0000-0002-5201-5509

Aldo P Maggioni http://orcid.org/0000-0003-2764-6779

Jolien W Roos-Hesselink http://orcid.org/0000-0002-6770-3830

\section{REFERENCES}

1 Therrien J, Barnes I, Somerville J. Outcome of pregnancy in patients with congenitally corrected transposition of the great arteries. Am J Cardiol 1999;84:820-4.

2 Guédès A, Mercier L-A, Leduc L, et al. Impact of pregnancy on the systemic right ventricle after a mustard operation for transposition of the great arteries. J Am Coll Cardiol 2004;44:433-7.

3 Connolly HM, Grogan M, Warnes CA. Pregnancy among women with congenitally corrected transposition of great arteries. J Am Coll Cardiol 1999;33:1692-5.

4 Clarkson PM, Wilson NJ, Neutze JM, et al. Outcome of pregnancy after the mustard operation for transposition of the great arteries with intact ventricular septum. J Am Coll Cardiol 1994;24:190-3.

5 Drenthen W, Pieper PG, Ploeg M, et al. Risk of complications during pregnancy after Senning or mustard (atrial) repair of complete transposition of the great arteries. Eur Heart J 2005;26:2588-95.

6 Roos-Hesselink JW, Ruys TPE, Stein Jl, et al. Outcome of pregnancy in patients with structural or ischaemic heart disease: results of a registry of the European Society of Cardiology. Eur Heart J 2013;34:657-65.

7 International Monetary Fund. World Economic Outlook - Recovery Strengthens, Remains Uneven. Washington, DC, 2014.

8 Hunt SA, Abraham WT, Chin MH. Focused update incorporated into the ACC/AHA 2005 guidelines for the diagnosis and management of heart failure in adults: a report of the American College of Cardiology Foundation/American Heart Association Task Force on Practice Guidelines: developed in collaboration with the International Society for Heart and Lung Transplantation. Circulation 2009;2009:e391-479.

9 Tranquilli AL, Brown MA, Zeeman GG, et al. The definition of severe and early-onset preeclampsia. statements from the International Society for the Study of Hypertension in Pregnancy (ISSHP). Pregnancy Hypertens 2013;3:44-7.

10 Roos-Hesselink J, Baris L, Johnson M, et al. Pregnancy outcomes in women with cardiovascular disease: evolving trends over 10 years in the ESC Registry Of Pregnancy And Cardiac disease (ROPAC). Eur Heart J 2019;40:3848-55.

11 Genoni M, Jenni R, Hoerstrup SP, et al. Pregnancy after atrial repair for transposition of the great arteries. Heart 1999;81:276-7.

12 Canobbio MM, Morris CD, Graham TP, et al. Pregnancy outcomes after atrial repair for transposition of the great arteries. Am J Cardiol 2006;98:668-72.

13 Metz TD, Jackson GM, Yetman AT. Pregnancy outcomes in women who have undergone an atrial switch repair for congenital d-transposition of the great arteries. Am J Obstet Gynecol 2011;205:273.e1-5. 
14 Gelson E, Curry R, Gatzoulis MA, et al. Pregnancy in women with a systemic right ventricle after surgically and congenitally corrected transposition of the great arteries. Eur J Obstet Gynecol Reprod Biol 2011;155:146-9.

15 Goland S, van Hagen IM, Elbaz-Greener G, et al. Pregnancy in women with hypertrophic cardiomyopathy: data from the European Society of Cardiology initiated Registry of Pregnancy and Cardiac disease (ROPAC). Eur Heart J 2017;38:2683-90.

16 Orwat S, Diller G-P, van Hagen IM, et al. Risk of Pregnancy in Moderate and Severe Aortic Stenosis: From the Multinational ROPAC Registry. J Am Coll Cardiol 2016;68:1727-37
17 Kowalik E, Klisiewicz A, Biernacka EK, et al. Pregnancy and long-term cardiovascular outcomes in women with congenitally corrected transposition of the great arteries. Int J Gynaecol Obstet 2014;125:154-7.

18 Cataldo S, Doohan M, Rice K, et al. Pregnancy following mustard or Senning correction of transposition of the great arteries: a retrospective study. BJOG 2016;123:807-13.

19 Cuypers JAAE, Eindhoven JA, Slager MA, et al. The natural and unnatural history of the mustard procedure: long-term outcome up to 40 years. Eur Heart $J$ 2014;35:1666-74. 